\title{
The development of early ascites is associated with shorter overall survival in patients with hepatocellular carcinoma treated with drug-eluting embolic chemoembolization
}

María Pipa-Muñiz ${ }^{1}$ Susana Sanmartino², Alicia Mesa², Carmen Álvarez-Navascués³, Maria-Luisa González-Diéguez³, Valle Cadahía ${ }^{3}$, José-Eduardo Rodríguez ${ }^{2}$, Florentino Vega ${ }^{2}$, Manuel Rodríguez ${ }^{3,4}$,

Serafin-Marcos Costilla-García ${ }^{2,4}$ and María Varela ${ }^{3^{*}}$ (i)

\begin{abstract}
Background: A single-centre cohort study was performed to identify the independent factors associated with the overall survival (OS) of hepatocellular carcinoma (HCC) patients treated with transarterial chemoembolization with drug-eluting beads (DEB-TACE).
\end{abstract}

Methods: A total of 216 HCC patients who underwent DEB-TACE from October 2008 to October 2015 at a tertiary hospital were consecutively recruited. The analysis of prognostic factors associated with overall survival after DEBTACE, stressing the role of post-TACE events, was performed.

Results: The objective response (OR) rate (Modified Response Evaluation Criteria in Solid Tumors (mRECIST) criteria) to the first DEB-TACE (DEB-TACE-1) was 70.3\%; the median OS from DEB-TACE-1 was 27 months (95\% confidence interval (CI), 24-30). In the multivariate analysis, tumor size, AFP $\leq 100 \mathrm{ng} / \mathrm{mL}$ and serum alkaline phosphatase were independent factors for survival following DEB-TACE-1. The most important clinical event associated with poor survival was the development of early ascites after DEB-TACE-1 (median OS, 17 months), which was closely related to the history of ascites, albumin and hemoglobin but not to tumour load or to response to therapy.

Conclusions: Early ascites post-DEB-TACE is associated with the survival of patients despite adequate liver function and the use of a supra-selective technical approach. History of ascites, albumin and hemoglobin are major determinants of the development of early ascites post-DEB-TACE.

Keywords: Hepatocellular carcinoma, DEB-TACE, Ascites, Response, Survival

\footnotetext{
* Correspondence: maria.varela.calvo@gmail.com; maria.varelac@sespa.es

${ }^{3}$ Liver Unit, Hospital Universitario Central de Asturias, 33011 Oviedo, Spain

Full list of author information is available at the end of the article
}

(c) The Author(s). 2020 Open Access This article is licensed under a Creative Commons Attribution 4.0 International License, which permits use, sharing, adaptation, distribution and reproduction in any medium or format, as long as you give appropriate credit to the original author(s) and the source, provide a link to the Creative Commons licence, and indicate if changes were made. The images or other third party material in this article are included in the article's Creative Commons licence, unless indicated otherwise in a credit line to the material. If material is not included in the article's Creative Commons licence and your intended use is not permitted by statutory regulation or exceeds the permitted use, you will need to obtain permission directly from the copyright holder. To view a copy of this licence, visit http://creativecommons.org/licenses/by/4.0/ The Creative Commons Public Domain Dedication waiver (http://creativecommons.org/publicdomain/zero/1.0/) applies to the data made available in this article, unless otherwise stated in a credit line to the data. 


\section{Background}

Hepatocellular carcinoma (HCC) is the sixth most common cancer worldwide and is the fourth-leading cause of cancer-related mortality [1, 2]. According to the European and American guidelines [3, 4], transarterial chemoembolization (TACE) is the first-line treatment for asymptomatic patients with Barcelona Clinic Liver Cancer (BCLC) B stage disease (which includes multinodular HCC beyond the Milan criteria, without portal invasion or extrahepatic disease) and compensated liver function. TACE is performed not only in BCLC-B patients but also in early-stage patients if resection, ablation or liver transplantation is not feasible. Thus, TACE candidates represent a heterogeneous group of patients with variable tumour burden and liver function [5].

TACE is an image-guided transcatheter tumour therapy that has an ischaemic and cytotoxic effect on tumour tissue. The use of drug-eluting embolic chemoembolization (DEB-TACE) is safe and effective [6, 7]. However, an improvement in the overall survival (OS) of DEB-TACE compared to that of conventional TACE has not been confirmed [8, 9].

Considering the heterogeneity of TACE candidates, patient selection must be carefully carried out. Underlying chronic liver disease is exacerbated by this procedure, especially in patients with diminished liver reserve [10]. Several algorithms have been recently reported to predict HCC prognosis in an attempt to optimize chemoembolization treatments, but few data have been obtained from DEB-TACE procedures [11-13]. Moreover, there is also scarce information about the influence of post-DEB-TACE events on OS and hepatic decompensation.

A prior meta-analysis of untreated patients in randomized clinical trials for $\mathrm{HCC}$ reported that ascites is strongly linked to a worse outcome in intermediate/advanced BCLC stages [14].

Some authors have suggested that a time-dependent covariate analysis that includes all the rounds of DEBTACE, clinically relevant events and subsequent therapies is needed to properly evaluate the factors that influence the survival of patients.

The aim of our study was to identify predictive factors for survival in HCC patients treated with DEB-TACE, taking into account the basal characteristics, the procedure, the response to treatment and the impact of events after the first DEB-TACE (DEB-TACE-1), in a timedependent covariate analysis.

\section{Methods}

\section{Patients}

From October 2008 to October 2015, patients with HCC diagnosed according to the European Association for the Study of the Liver (EASL) guidelines who were selected for DEB-TACE were referred to a tertiary academic university hospital and were prospectively registered.

The inclusion criteria were as follows: 1) HCC that was diagnosed in the early stage but was not eligible for resection, ablation or liver transplant; 2) HCC with an intermediate BCLC stage; 3) compensated cirrhosis with normal or mildly altered liver function, without ascites or encephalopathy at the time of DEB-TACE; 4) an asymptomatic status, with an ECOG performance status 0; and 5) approval for DEB-TACE after evaluation by the multidisciplinary tumour board. Portal thrombosis, impaired liver function, current decompensated cirrhosis, performance status $>0$, extrahepatic disease and contraindication or impossibility for catheterization or chemoembolization were considered exclusion criteria. Patients included in clinical trials or awaiting liver transplantation for whom DEB-TACE was used as a bridge therapy were excluded.

Clinically significant portal hypertension (CSPH) was defined as the presence of prior cirrhosis decompensation, oesophageal or gastric varices or low platelet counts (lower than $100 \times 10^{9} / \mathrm{L}$ ) [15] and early ascites as the appearance of ascites after the first round of DEBTACE.

Clinical, biochemical and radiological examinations were performed at baseline and prior to every DEBTACE procedure. No general sedation was used, and no antibiotic prophylaxis was indicated, except in patients with prior endoscopic retrograde cholangiopancreatography. If the prothrombin rate was lower than $50 \%$ or if the platelet count was less than $50 \times 10^{9} / \mathrm{L}$, fresh-frozen plasma was administered and/or platelet infusion was performed. Pain during the procedure was individually managed, and patients were discharged $24 \mathrm{~h}$ later, unless complications were observed.

\section{DEB-TACE procedure}

Drug-eluting beads ${ }^{\ominus}$ were loaded with doxorubicin following the manufacturer's instructions the day before the procedure. Particles that were $300-500 \mu \mathrm{m}(\mu \mathrm{m})$ were used until March 2013, when these particles were replaced by $100-300-\mu \mathrm{m}$ beads to further penetrate the tumour [16]. If embolization was not completely achieved unloaded microspheres were employed to complete the artery obstruction.

Selective angiography of the common hepatic artery was carried out as well as of the right and left hepatic arteries. A supraselective approach for tumour vessels was achieved by using a Progreat 2.7 (Terumo ${ }^{\circ}$ ) microcatheter with $0.21,0.16$ or 0.14 Terumo $^{\circ}$ microwires, and DC-Beads ${ }^{\oplus}$ were then injected. After angiographic control, the $4 \mathrm{~F}$ catheter and the introducer were removed, and manual compression was applied. 
Starting in February 2015, Cone-Beam-CT software (CBCT, Syngo DynaCT, Siemens ${ }^{\odot}$ ) with contrast injection was employed to help during vascular catheterization, especially if the nodule was not visible at basal angiography or was in intersegmental nodules, when lesions were proximal to the diaphragm and when extrahepatic vascularization was evaluated. Once the procedure was finished, CBCT without intraarterial contrast was used to evaluate embolization.

\section{Follow-up}

All patients received a clinical, analytical and radiological follow-up 6 weeks after each DEB-TACE procedure. Response to treatment was evaluated by contrast-enhanced computed tomography (CT) according to the Modified Response Evaluation Criteria in Solid Tumors (mRECIST) criteria [17], and results were presented to the multidisciplinary tumour board. If partial response, stable disease or treatable progression were observed, a subsequent DEB-TACE was planned [18]. Patients with untreatable progression were evaluated for systemic therapy. Objective response (OR) was defined as the sum of complete response and partial response. The disease control rate (DCR) was defined as the OR as well as the stable disease rate.

\section{Statistical analysis}

Quantitative variables are expressed as the median and interquartile range, and categorical variables are expressed as the count and proportion. Continuous quantitative variables were categorized according to the median value for the analysis. Differences between subgroups were evaluated with a Chi-squared test, Fisher's exact test and U-Mann Whitney, depending on the type of variable. A conventional $p$-value of less than 0.05 was considered significant.

Patient survival probability was estimated using the Kaplan-Meier method. OS was calculated from DEBTACE-1 to death or to the end of follow-up for two periods: from baseline $\left(\mathbf{t}_{\mathbf{0}}\right)$, taking into account clinical, demographic and radiological data prior to DEB-TACE1 , and from 6 weeks after DEB-TACE-1 $\left(\mathbf{t}_{\mathbf{1}}\right)$, also considering complications and the radiological response to treatment. Variables with univariate significance $(p<0.10)$ and clinical relevance were included in the Cox proportional hazards model for the multivariable analysis with the forward selection method.

The factors associated with the development of early ascites were analysed, bearing in mind the baseline characteristics, the response to treatment and other complications. The time was censored at ascites development, death or the second DEB-TACE (DEBTACE-2).
All calculations were performed with SPSS version 23 (SPSS Inc., Chicago, IL).

An additional time-dependent covariate analysis was performed by using $\mathbf{R}$ (www.r-project.org) to identify factors associated with mortality. A backward method based on the Akaike information criteria was employed.

The protocol conformed to the ethical guidelines of the 1975 Declaration of Helsinki and was approved by the Ethics Committee of the Hospital Universitario Central de Asturias (Approval No. 120/19). This prospective database has been retrospectively reviewed and because of the retrospective nature of the study consent retrieval was waived.

\section{Results}

From October 2008 to October 2015, 242 consecutive patients with $\mathrm{HCC}$ who were diagnosed according to EASL guidelines were referred for DEB-TACE, but only 216 of these patients met the inclusion criteria. Table 1 summarizes the baseline characteristics. The predominant aetiology of liver disease was alcohol (45\%), followed by hepatitis $\mathrm{C}$ virus infection (36\%). Most of the patients were BCLC-B (58\%) and Child-Pugh class A 5 (64\%). Sixty-one percent had oesophageal varices, $32 \%$ were on a low-salt diet and / or diuretic and 73\% presented $\mathrm{CSPH}$.

The median number of DEB-TACE sessions was 2 (IQR, 1-3), and a total of 443 procedures were performed (Fig. 1).

The median follow-up was 26.5 months, and follow-up was censored at death, loss to follow-up or the last visit (April 1, 2019).

\section{Response to treatment}

According to the mRECIST criteria at week 6 after DEBTACE-1, complete response was achieved in 55 patients (26\%), partial response in 97 patients (45\%) and stable disease in 24 (11\%). In contrast, 35 patients (16\%) presented progressive disease after DEB-TACE-1. 35\% of those migrated to BCLC-C stage. In 5 patients (2\%), mRECIST was not available.

\section{Follow-up and post-DEB-TACE events}

During the follow-up, DEB-TACE was discontinued in 71 patients after the first session. Figure 1 shows the different causes for the discontinuation of DEB-TACE after the first or subsequent rounds. Post-procedure events within the first 90 days after DEB-TACE-1 are described in Supplementary Table 1. A total of 73 of 216 patients experienced post-DEB-TACE-1 events (33.7\%): 23 patients $(31.5 \%)$ experienced radiological events, 41 patients (56.2\%) experienced clinical events and 9 patients (12.3\%) experienced both clinical and 
Table 1 Baseline characteristics of the patients $(n=216)$

\begin{tabular}{|c|c|}
\hline Age (yr), median (range), IQR & $70(38-84), 63-76$ \\
\hline Gender (Male/Female), n (\%) & $180(83) / 36(17)$ \\
\hline Alcohol/HCV/other etiologies, n (\%) & $97(45) / 78(36) / 41(19)$ \\
\hline Prior radiological ascites (no / yes), n (\%) & $198(92) / 18(8)$ \\
\hline Diuretic treatment (no/yes, not available), n (\%) & $133(62) / 67(31) / 16(7)$ \\
\hline Esophageal varices (yes/no/not available), n (\%) & $72(33) / 131(61) / 13(6)$ \\
\hline Child-Pugh (A5/A6/B/ not available), n (\%) & $139(64) / 39(19) / 18(7.4) / 20(9.6)$ \\
\hline BCLC-B (O/A/B), n (\%) & $10(5) / 77(37) / 129(58)$ \\
\hline Bilirubin (mg/dL), median (range), IQR & $1(0.2-5.4), 0.93-1.33$ \\
\hline Albumin, (g/L), median (range), IQR & 40 (27-49), 36-43 \\
\hline AFP (ng/mL), median (range), IQR & $12.8(0.3-13-000), 4.9-60.3$ \\
\hline $\mathrm{Cr}(\mathrm{mg} / \mathrm{dL})$, median (range), IQR & $0.84(0.43-3.96), 0.72-0.99$ \\
\hline Sodium (mEq/L), median (range), IQR & $141(130-146), 138-142$ \\
\hline AST (IU/L), median (range), IQR & $50(15-285), 32-84$ \\
\hline ALT (IU/L), median (range), IQR & $38(7-278), 25-76.5$ \\
\hline GGT (IU/L), median (range), IQR & $120(16-2011), 67-212$ \\
\hline AP (IU/L), median (range), IQR & 108 (36-370), 86.5-138.5 \\
\hline PT (\%), median (range), IQR & 84 (36-118), 75-94 \\
\hline Platelets $\left(\times 10^{9} / \mathrm{L}\right)$, median (range), IQR & $113(22-460), 79-159$ \\
\hline Hemoglobin (g/dL), median (range), IQR & $13.6(7.6-17.9), 12.4-14.9$ \\
\hline Clinically Significant Portal Hypertension (yes/no), n & $157(73) / 59(27)$ \\
\hline Main nodule diameter (mm), median (range), IQR & $35(11-100), 23-48$ \\
\hline Previous treatment (ablation/resection), n (\%) & $44 / 8$ \\
\hline ALBI 1/2/3/not available, $n$ & $81 / 96 / 1 / 38$ \\
\hline Beads size $300-500 \mu m / 100-300 \mu m, n$ & $135 / 81$ \\
\hline Use of Cone Beam CT (no/yes), $n$ & $187 / 29$ \\
\hline Dose of doxorubicin (mg), median (range), IQR & 90 (7.5-150), 70-140 \\
\hline
\end{tabular}

Yr Year, IQR Interquartile range, HCV Hepatitis C virus, BCLC Barcelona Clinic Liver Cancer, AFP Alpha-fetoprotein, Cr Serum creatinine, AST Aspartate aminotransferase, ALT Alanine aminotransferase, GGT Gamma-glutamyl-transpeptidase, AP Alkaline phosphatase, $P T$ Prothrombin time

radiological events. Ascites was the most frequent adverse event and was present in 27 patients.

At the end of follow-up, 27 patients were alive; 70 patients had moved to sorafenib and 9 to second-line regorafenib.

\section{Overall survival}

The median OS from DEB-TACE-1 was 27 months (95\% confidence interval (CI), 24.193-29.807) (Fig. 2). The cumulative survival rates were $82,58,32$ and $16 \%$ at 1 , 2, 3 and 5 years, respectively.

- Univariate and multivariate analyses prior to DEBTACE-1 $\left(\mathbf{t}_{\mathbf{0}}\right)$ and at 6 weeks after DEB-TACE-1 ( $\left.\mathbf{t}_{\mathbf{1}}\right)$ are shown in Tables 2 and 3. Supplementary Table 2 collects the variable values in $\mathbf{t} 1$.The independent factors associated with OS at $\mathbf{t}_{\mathbf{0}}$ were tumor size $<36.5 \mathrm{~mm}$ (cut-off estimated by AUROC) 30 vs 22 months HR 0.72 (95\% CI $0.53-0.98, p=0.039)$, basal AFP $\leq 100 \mathrm{ng} / \mathrm{mL}$ (arbitrary value) 29 vs 18 months HR 0.67 (95\% CI 0.47$0.96, p=0.029)$ and basal alkaline phosphatase $<108 \mathrm{IU} /$ L (median value) 32 vs 24 months HR 0.64 (95\% CI 0.47-0.88, $p=0.005$ ). By contrast, the independent factors associated with OS at $\mathbf{t}_{\mathbf{1}}$ were post-TACE albu$\min \leq 35 \mathrm{~g} / \mathrm{L}$ (arbitrary cut-off) 22 vs 30 months HR 1.5 (95\% CI 1.1-2.2, $p=0.02$ ), post TACE AFP $\leq 100 \mathrm{ng} / \mathrm{mL}$ (arbitrary cut-off) 29 vs 12 months HR 0.65 (95\% CI $0.45-0.93, p=0.02)$ and absence of development of ascites (28 vs 17 months, HR 0.43 , 95\% CI $0.27-0.68$, $p<0.001)$. There were four additional models, 2 of them including objective response, detailed in Table 3.

\section{Post-DEB-TACE events}

The most important clinical event associated with shorter survival was the presence of ascites after DEBTACE-1 (Fig. 3). Patients with ascites $(n=27)$ had a median OS of 17 months (95\% CI, 8.566-25.434; 


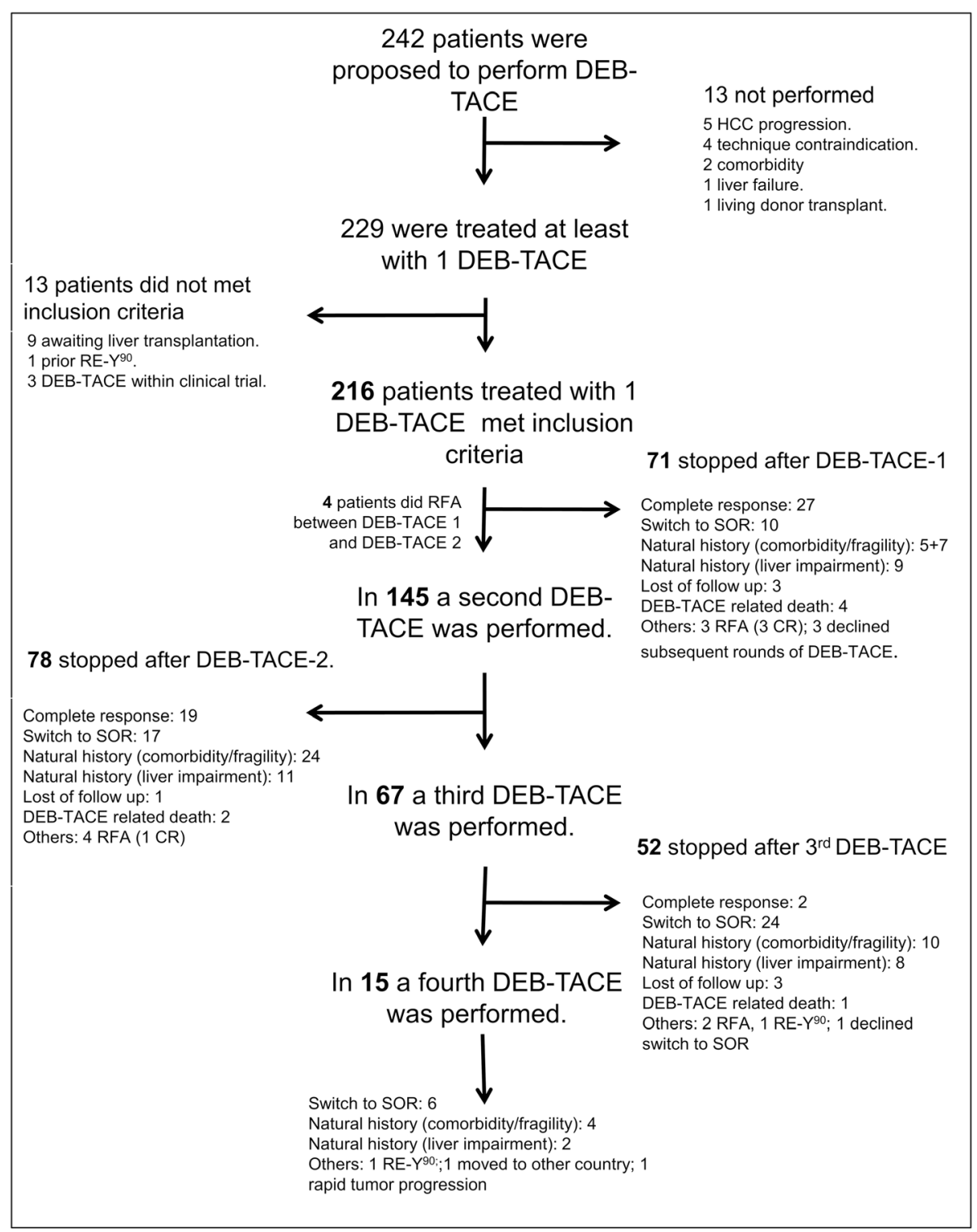

RE-Y90: radioembolization Yttrium 90. SOR: sorafenib. RFA: radiofrequency ablation

Fig. 1 Flowchart of patients enrolled in the study

$p<0.05)$; in contrast, patients without ascites had a median OS of 28 months (95\% CI, 25.519-30.481). Cumulative survival rates at $1,2,3$ and 5 years are shown in Fig. 3.

Baseline characteristics associated with the development of ascites are shown in Supplementary Table 3. History of ascites decompensation, haemoglobin and albumin were independently related to the development of early ascites (Table 4). The development of ascites after DEB-TACE was independent of the radiological response (the OR rate was similar in patients who developed ascites, indicating that this was not related to tumour progression, $p=0.13$ ). Lastly, 9 patients recovered from hepatic decompensation and received DEBTACE-2. The median time between decompensation and TACE retreatment was 52 days (range 181, IQR 46.5-132).

In the time-dependent covariate analysis, the variables that were independently associated with survival were basal alpha-fetoprotein (HR, 1.66; 95\% CI, 1.31-2.10; $p<0.001$ ), time-dependent bilirubin (HR, 4.47; 95\% CI, 1.80-11.09; $p<0.001)$ and time-dependent alkaline phosphatase (HR, 1.68; 95\% CI, 1.41-2.01; $p<0.001$ ) (Supplementary Tables 4 and 5 and Supplementary figure 1). 


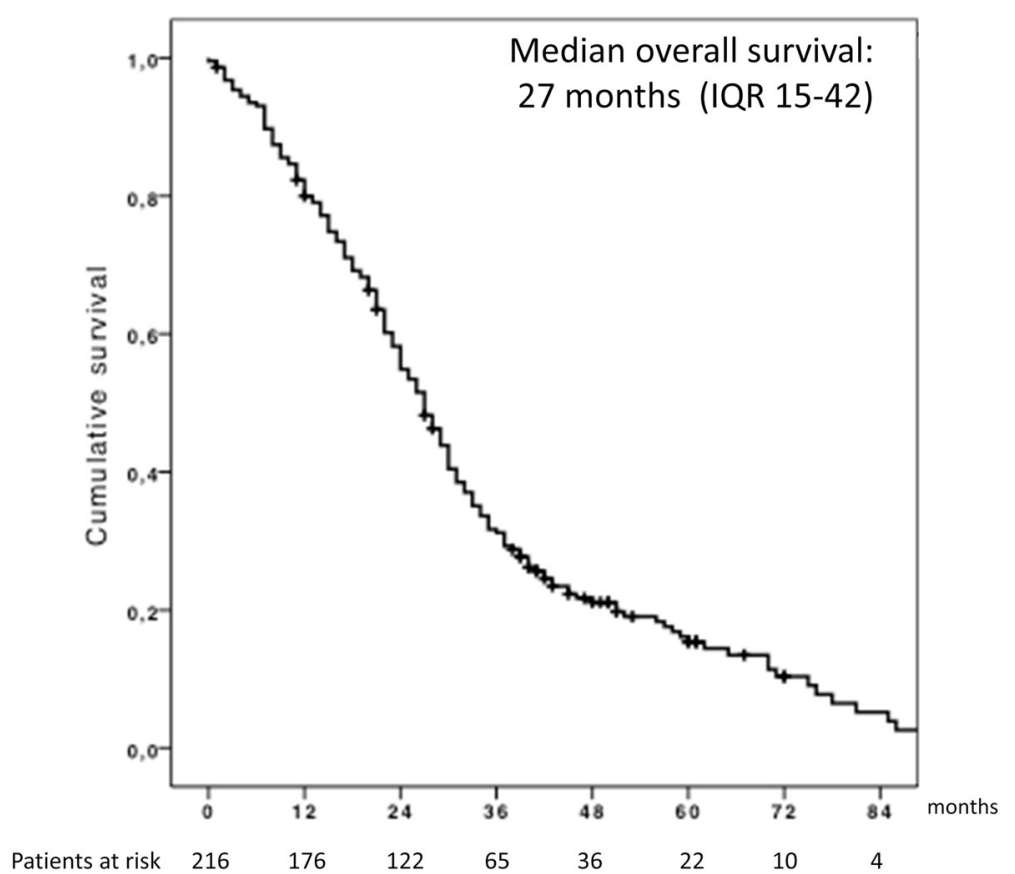

Fig. 2 Kaplan-Meier graph with the overall survival of the cohort

\section{Discussion}

Several publications have described the safety of DEBTACE [6-9], but an in-depth analysis of the impact of adverse events on patient progression has not been examined. Our study determined that the development of early ascites was negatively related to the overall survival of compensated patients treated with DEB-TACE. This finding was related to low albumin, low haemoglobin and prior episodes of clinical ascites. The presence of significant portal hypertension and/or worse liver function might suggest that patients are predisposed to complications in chemoembolization procedures and to the consequent impairment in OS. Currently, the presence of CSPH precludes patients from undergoing surgical resection for HCC [19], but less attention has been paid to other loco-regional therapies. However, two studies have recently reported that CSPH is a major negative prognostic factor in patients treated with DEB-TACE $[10,20]$.

In our clinical practice, patients with previous decompensation that remain compensated for more than 6 months are not excluded for treatment with DEB-TACE. That is the case in 71 patients with alcohol related cirrhosis with a first episode of hepatic decompensation that are asymptomatic and compensated after alcohol withdrawal. It should be noted that the OS of this cohort was lower than that at other sites [21-29] (Supplementary Table 6), despite similar patient selection, supra-selective procedures and response to therapy. We speculate that although alcohol aetiology is not an independent predictor of survival, alcohol consumption can impair liver function due to acute-on-chronic liver failure [30] or alcoholic hepatitis [31, 32]. The poor prognosis of alcohol-related HCC has been specifically observed in some French cohort studies [33, 34] and in patients treated with $\mathrm{Y}^{90}$ radioembolization in the SORAMIC study [35]. Indeed, these patients had more comorbidities than those affected by hepatitis $\mathrm{C}$, and in some cases, refused to undergo additional sessions of DEB-TACE. In our series, 6 patients presented a second primary tumour after DEB-TACE (1 pyriform sinus, 1 bladder, 1 colorectal and 3 lung cancers), and $13 \%$ of patients died from other causes that were not related to tumour progression or cirrhosis decompensation. Finally, some post-DEB-TACE events were handled out of the tertiary hospital, and the suboptimal care of cirrhosis complications could have influenced the survival of our patients.

Alkaline phosphatase has resulted as independent factors for survival following DEB-TACE-1, together with tumor size and AFP. This enzyme is a variation marker for embryonic stem cell and could indicate the proliferation of tumor cells, playing an important role in cell cycle regulation, cell proliferation and tumor formation. High levels of AP have been related to poor prognosis of $\mathrm{HCC}$ in different populations $[36,37]$.

This study had several weaknesses. This was an observational cohort study that was performed over many 
Table 2 Predictors of overall survival from DEB-TACE-1 (period $t_{0}$ ) with pre-DEB-TACE variables $(n=216)$ based on multivariate Cox regression

\begin{tabular}{|c|c|c|c|c|c|c|c|c|}
\hline \multirow{3}{*}{$\frac{T_{0}}{\text { Variable }}$} & \multirow{3}{*}{ Categories } & \multirow{3}{*}{$n=216$} & \multicolumn{3}{|c|}{ Univariate analysis } & \multicolumn{3}{|c|}{ Multivariate analysis } \\
\hline & & & \multicolumn{2}{|c|}{ Overall survival (months) } & \multirow[t]{2}{*}{$p$-value } & \multirow[t]{2}{*}{ HR } & \multirow[t]{2}{*}{ HR 95\% Cl } & \multirow[t]{2}{*}{$p$-value } \\
\hline & & & median & median 95\% Cl & & & & \\
\hline \multirow[t]{2}{*}{ Esophageal varices } & No varices & 72 & 30 & $22.7-37.2$ & 0.025 & & & \\
\hline & Varices & 131 & 25 & $21.2-28.8$ & & & & \\
\hline \multirow{2}{*}{$\geq 3$ nodules } & No & 180 & 27 & $23.8-30.2$ & 0.029 & & & \\
\hline & Yes & 33 & 23 & $18.6-27.4$ & & & & \\
\hline \multirow[t]{2}{*}{ Tumor size ${ }^{\mathrm{b}}(\mathrm{mm})$} & $\leq 36.5$ & 128 & 30 & $26.9-33.1$ & 0.025 & 0.72 & $0.53-0.98$ & 0.039 \\
\hline & $>36.5$ & 84 & 22 & $17.5-26.5$ & & & & \\
\hline \multirow[t]{2}{*}{ AFP pre-TACE ${ }^{a}(\mathrm{ng} / \mathrm{mL})$} & $\leq 12.8$ & 105 & 30 & $25.8-34.2$ & 0.008 & & & \\
\hline & $>12.8$ & 105 & 23 & $19.2-26.8$ & & & & \\
\hline \multirow[t]{2}{*}{ AFP pre-TACE $(\mathrm{ng} / \mathrm{mL})$} & $\leq 100$ & 165 & 29 & $26.1-31.8$ & 0.009 & 0.67 & $0.47-0.96$ & 0.029 \\
\hline & $>100$ & 44 & 18 & $13.4-22.6$ & & & & \\
\hline \multirow[t]{2}{*}{ AFP pre-TACE (ng/mL) } & $\leq 200$ & 181 & 29 & $26.5-31.5$ & $<0.001$ & & & \\
\hline & $>200$ & 28 & 15 & $11.1-18.9$ & & & & \\
\hline \multirow[t]{2}{*}{ AFP pre-TACE (ng/mL) } & $\leq 400$ & 192 & 28 & $25.2-30.8$ & 0.002 & & & \\
\hline & $>400$ & 17 & 13 & $8.2-17.8$ & & & & \\
\hline \multirow[t]{2}{*}{ Bil pre-TACE ${ }^{a}(\mathrm{mg} / \mathrm{dL})$} & $\leq 1$ & 130 & 28 & $24.2-31.8$ & 0.052 & & & \\
\hline & $>1$ & 79 & 25 & $21.3-28.7$ & & & & \\
\hline \multirow[t]{2}{*}{ Bil pre-TACE (mg/dL) } & $\leq 2$ & 191 & 27 & $23.8-30.1$ & 0.47 & & & \\
\hline & $>2$ & 17 & 27 & $23.1-30.9$ & & & & \\
\hline \multirow[t]{2}{*}{ Alb pre-TACE ${ }^{a}(\mathrm{~g} / \mathrm{L})$} & $\leq 40$ & 110 & 24 & $20.3-27.3$ & 0.112 & & & \\
\hline & $>40$ & 98 & 28 & $24.34-31.6$ & & & & \\
\hline \multirow[t]{2}{*}{ Alb pre-TACE (g/L) } & $\leq 35$ & 39 & 23 & $18.6-27.4$ & 0.021 & & & \\
\hline & $\geq 35$ & 169 & 29 & $25.9-32.04$ & & & & \\
\hline \multirow[t]{2}{*}{ AP preTACE ${ }^{a}$ (IU/L) } & $\leq 108$ & 105 & 32 & $28.01-35.9$ & $<0.001$ & 0.64 & $0.47-0.88$ & 0.005 \\
\hline & $>108$ & 105 & 24 & $20.8-27.2$ & & & & \\
\hline \multirow[t]{2}{*}{ Hb pre-TACE $(\mathrm{g} / \mathrm{dL})$} & $\leq 13.6$ & 108 & 24 & $19.02-28.9$ & 0.155 & & & \\
\hline & $>13.6$ & 105 & 28 & $25.6-30.3$ & & & & \\
\hline \multirow[t]{2}{*}{ Platelets preTACE, $10^{\wedge 9} / \mathrm{L}$} & $\leq 100$ & 90 & 26 & $22.3-29.6$ & 0.93 & & & \\
\hline & $>100$ & 121 & 27 & $22.7-31.2$ & & & & \\
\hline \multirow[t]{2}{*}{ Ascites preTACE } & No & 198 & 27 & $24.4-29.6$ & 0.068 & & & \\
\hline & Yes & 18 & 21 & $16.9-25.01$ & & & & \\
\hline \multirow[t]{2}{*}{$\mathrm{CSPH}$} & No & 59 & 30 & $22.5-37.5$ & 0.045 & & & \\
\hline & Yes & 157 & 26 & $22.3-29.7$ & & & & \\
\hline
\end{tabular}

Cl Confidence interval, HR Hazard ratio, TACE Transarterial chemoembolization, BCLC Barcelona Clinic Liver Cancer, CSPH Clinically significant portal hypertension., AFP Alpha-fetoprotein, Bil Bilirubin, Alb Albumin, AP Alkaline phosphatase, $\mathrm{Hb}$ Hemoglobin

${ }^{a}$ The median values were used as a cut-off for continuous variables. ${ }^{\mathrm{b}}$ Tumor size estimated by AUROC

Other variables evaluated: sex $(p=0.156)$, etiology $(0.197)$; diabetes $(p=0.929) ; \operatorname{AST}(p=0.340) ; \operatorname{ALT}(p=0.791) ; \operatorname{GGT}(p=0.289) ; \operatorname{Creatinine}(p=0.847) ;$ Na $(p=$ $0.944)$; CBCT use $(p=0.495)$; DEB size $(p=0.283)$

years, during which changes in the state-of-the-art technology occurred. However, the multidisciplinary core team and the main interventional radiologists did not change over the course of the study. Furthermore, neither the change in the DEB particles size (March
2013) nor the introduction of CBCT (February 2015) have influenced the objective response rate or the global overall survival (data not shown).

The second weakness was that no clinical events were identified in the time-dependent covariate analysis. 
Table 3 Predictors of overall survival in the $t_{1}$ period (from DEB-TACE- 1 assessment) including pre and post-procedure variables $(n=$ 216) based on multivariate Cox regression

\begin{tabular}{|c|c|c|c|c|c|c|c|c|}
\hline \multirow{3}{*}{$\frac{T_{1}}{\text { Variable }}$} & \multirow{3}{*}{ Categories } & \multirow{3}{*}{$n=216$} & \multicolumn{3}{|c|}{ Univariate analysis } & \multicolumn{3}{|c|}{ Multivariate analysis } \\
\hline & & & \multicolumn{2}{|c|}{ overall survival, months } & \multirow[t]{2}{*}{$p$-value } & \multirow[t]{2}{*}{ HR } & \multirow[t]{2}{*}{$\mathrm{HR}, 95 \% \mathrm{Cl}$} & \multirow[t]{2}{*}{$p$-value } \\
\hline & & & median & median, 95\% Cl & & & & \\
\hline \multirow[t]{2}{*}{ Number nodules } & $\leq 3$ & 165 & 27 & $23.2-30.8$ & 0.07 & & & \\
\hline & $>3$ & 51 & 24 & $18.4-26.9$ & & & & \\
\hline \multirow[t]{2}{*}{ Main nodule size ${ }^{b}, \mathrm{~mm}$} & $\leq 36.5$ & 110 & 30 & $26.5-33.5$ & 0.005 & 0.59 & $0.45-0.84$ & 0.003 \\
\hline & $>36.5$ & 103 & 22 & $18.9-25.03$ & & 0.65 & $0.46-0.92$ & 0.013 \\
\hline \multirow[t]{2}{*}{ EV } & No & 72 & 30 & $22.8-37.2$ & 0.03 & & & \\
\hline & Yes & 144 & 26 & $22.8-29.2$ & & & & \\
\hline \multirow[t]{2}{*}{ CSPH } & No & 61 & 30 & $24.9-35.1$ & 0.05 & & & \\
\hline & Yes & 153 & 25 & $21.4-28.6$ & & & & \\
\hline \multirow[t]{2}{*}{ Gender } & Female & 37 & 31 & $21.5-40.5$ & 0.14 & & & \\
\hline & Male & 179 & 27 & $23.8-30.1$ & & & & \\
\hline \multirow[t]{2}{*}{ Albumin preTACE $(g / L)$} & $\leq 40$ & 110 & 24 & $20.3-27.7$ & 0.2 & 0.61 & $0.4-0.93$ & 0.023 \\
\hline & $>40$ & 98 & 28 & $24.1-31.8$ & & & & \\
\hline \multirow[t]{4}{*}{ AP preTACE ${ }^{\mathrm{a}}$ (IU/L) } & $\leq 108$ & 105 & 32 & $28.01-35.9$ & $<0.001$ & 0.65 & $0.44-0.94$ & 0.02 \\
\hline & $>108$ & 104 & 24 & $20.7-27.2$ & & 0.56 & $0.39-0.79$ & 0.001 \\
\hline & & & & & & 0.54 & $0.38-0.76$ & 0.001 \\
\hline & & & & & & 0.59 & $0.43-0.8$ & 0.001 \\
\hline \multirow[t]{2}{*}{$\operatorname{AFP}$ preTACE $(\mathbf{n g} / \mathrm{mL})$} & $\leq 12.8$ & 105 & 30 & $25.7-34.2$ & 0.009 & 0.66 & $0.46-0.94$ & 0.002 \\
\hline & $\leq 12.8$ & 104 & 23 & $19.3-26.7$ & & 0.7 & $0.49-0.98$ & 0.04 \\
\hline \multirow[t]{2}{*}{ Ascites preTACE } & No & 198 & 28 & $25.3-30.6$ & 0.06 & 0.39 & $0.19-0.76$ & 0.006 \\
\hline & Yes & 18 & 20 & $16.1-23.9$ & & & & \\
\hline \multirow[t]{2}{*}{ Doxorubicin dose $^{\mathrm{a}}(\mathrm{mg})$} & $\leq 90$ & 95 & 29 & $25.4-32.5$ & 0.03 & & & \\
\hline & $>90$ & 94 & 24 & $20.5-27.6$ & & & & \\
\hline CBCT & No & 187 & 27 & $23.7-30.3$ & 0.25 & & & \\
\hline & Yes & 29 & 24 & $19.4-28.6$ & & & & \\
\hline Particle size, $\mu \mathrm{m}$ & $300-500$ & 135 & 26 & $23.2-28.8$ & 0.53 & & & \\
\hline & $100-300$ & 81 & 29 & $23.6-34.4$ & & & & \\
\hline Post-TACE-1 events & No & 143 & 29 & $26.3-31.6$ & 0.005 & & & \\
\hline & Yes & 73 & 22 & $16.3-27.7$ & & & & \\
\hline $\mathrm{Hb}$ post-TACE-1 ${ }^{\mathrm{a}}(\mathrm{g} / \mathrm{dL})$ & $\leq 13.4$ & 109 & 26 & $20.2-31.8$ & 0.83 & & & \\
\hline & $>13.4$ & 98 & 28 & $24.3-31.7$ & & & & \\
\hline Platelets post-TACE- $1^{\mathrm{a}} \times 10^{\wedge} \mathrm{g} / \mathrm{L}$ & $\leq 108.5$ & 103 & 26 & $21.4-30.6$ & 0.66 & & & \\
\hline & $>108.5$ & 103 & 27 & $22.4-31.5$ & & & & \\
\hline Platelets post-TACE- $1 \times 10^{\wedge} 9 / \mathrm{L}$ & $\leq 100$ & 87 & 26 & $21.3-30.7$ & 0.75 & & & \\
\hline & $>100$ & 119 & 27 & $22.7-31.2$ & & & & \\
\hline Albumin post-TACE-1 ${ }^{\mathrm{a}}(\mathrm{g} / \mathrm{dL})$ & $\leq 38$ & 106 & 21 & $18.7-23.3$ & $<0.001$ & 2.5 & $1.6-3.9$ & $<0.001$ \\
\hline & $>38$ & 102 & 35 & $28.8-41.2$ & & & & \\
\hline Albumin pos-TACE $1 \mathrm{~g} / \mathrm{dL}$ & $\leq 35$ & 54 & 22 & $18.5-25.5$ & 0.001 & 1.5 & $1.1-2.2$ & 0.02 \\
\hline & $>35$ & 154 & 30 & $26.9-33.1$ & & & & \\
\hline$\triangle$ Albumin $\mathrm{g} / \mathrm{dL}$ & $<0$ & 138 & 25 & $21.7-28.3$ & 0.07 & & & \\
\hline & 0 & 22 & 37 & $27.5-46.5$ & & & & \\
\hline & $>0$ & 40 & 29 & $24.8-33.1$ & & & & \\
\hline AFP post-TACE $1^{\mathrm{a}} \mathrm{ng} / \mathrm{mL}$ & $\leq 8.4$ & 105 & 30 & $25.4-34.5$ & 0.025 & & & \\
\hline & $>8.4$ & 104 & 24 & $20.5-27.5$ & & & & \\
\hline AFP post-TACE $1 \mathrm{ng} / \mathrm{mL}$ & $\leq 100$ & 183 & 29 & $26.4-31.6$ & $<0.001$ & 0.65 & $0.45-0.93$ & 0.02 \\
\hline & $>100$ & 26 & 12 & $8.3-15.7$ & & 0.67 & $0.47-0.97$ & 0.03 \\
\hline AFP post-TACE $1 \mathrm{ng} / \mathrm{mL}$ & $\leq 200$ & 192 & 29 & $26.5-31.5$ & 0.005 & & & \\
\hline & $>200$ & 171 & 14 & $9.9-18.03$ & & & & \\
\hline
\end{tabular}


Table 3 Predictors of overall survival in the $t_{1}$ period (from DEB-TACE- 1 assessment) including pre and post-procedure variables $(n=$ 216) based on multivariate Cox regression (Continued)

\begin{tabular}{|c|c|c|c|c|c|c|c|c|}
\hline \multirow{2}{*}{$\frac{T_{1}}{\text { AFP post-TACE } 1 \mathrm{ng} / \mathrm{mL}}$} & \multirow[b]{2}{*}{$\leq 400$} & \multirow[b]{2}{*}{159} & \multicolumn{2}{|c|}{ Univariate analysis } & \multirow{2}{*}{$<0.001$} & \multicolumn{2}{|c|}{ Multivariate analysis } & \\
\hline & & & 29 & $26.5-31.5$ & & & & \\
\hline & $>400$ & 13 & 12 & $7.3-16.7$ & & & & \\
\hline \multirow[t]{3}{*}{$\triangle$ AFP $n g / m L$} & $<0$ & 139 & 28 & $24.7-31.3$ & 0.23 & & & \\
\hline & 0 & 6 & 14 & $5.6-22.4$ & & & & \\
\hline & $>0$ & 57 & 27 & $22.1-31.8$ & & & & \\
\hline \multirow[t]{2}{*}{ Bilirubin post-TACE $1^{\mathrm{a}} \mathrm{mg} / \mathrm{dL}$} & $\leq 1$ & 140 & 30 & $25.4-34.5$ & 0.01 & & & \\
\hline & $>1$ & 71 & 24 & $20.6-27.4$ & & & & \\
\hline \multirow[t]{2}{*}{ Bilirubin pos. TACE $1 \mathrm{mg} / \mathrm{dL}$} & $\leq 2$ & 194 & 28 & $25.3-30.7$ & 0.03 & & & \\
\hline & $>2$ & 17 & 15 & $5.6-24.4$ & & & & \\
\hline \multirow[t]{3}{*}{$\Delta$ Bilirubin mg/dL } & $<0$ & 74 & 27 & $21.4-32.6$ & 0.003 & & & \\
\hline & 0 & 62 & 34 & $26.1-41.9$ & & & & \\
\hline & $>0$ & 67 & 23 & $20.1-25.9$ & & & & \\
\hline \multirow[t]{2}{*}{ AST post-TACE $1^{\mathrm{a}} \mathrm{IU} / \mathrm{L}$} & $\leq 47$ & 104 & 27 & $22.5-31.5$ & 0.67 & & & \\
\hline & $>47$ & 100 & 29 & $24.7-33.2$ & & & & \\
\hline \multirow[t]{2}{*}{ ALT post-TACE $1^{\mathrm{a}} \mathrm{IU} / \mathrm{L}$} & $\leq 35$ & 104 & 26 & $22.7-29.2$ & 0.5 & & & \\
\hline & $>35$ & 103 & 29 & $25.8-32.2$ & & & & \\
\hline \multirow[t]{2}{*}{ GGT post-TACE $1^{\mathrm{a}}$ IU/L } & $\leq 133$ & 105 & 29 & $21.7-36.3$ & 0.23 & & & \\
\hline & $>133$ & 100 & 27 & $24.1-29.8$ & & & & \\
\hline \multirow[t]{2}{*}{ AP post-TACE $1^{a}$ IU/L } & $\leq 128$ & 102 & 33 & $28.3-37.6$ & $<0.001$ & & & \\
\hline & $>128$ & 102 & 20 & $11.6-28.3$ & & & & \\
\hline \multirow[t]{3}{*}{$\triangle$ AP post-TACE 1 IU/L } & $<0$ & 57 & 30 & $23.7-36.3$ & 0.66 & & & \\
\hline & 0 & 2 & & & & & & \\
\hline & $>0$ & 139 & 27 & $23.8-30.2$ & & & & \\
\hline \multirow[t]{2}{*}{ Creatinine post-TACE $1^{\mathrm{a}} \mathrm{mg} / \mathrm{dL}$} & $\leq 0.79$ & 104 & 28 & $24.2-31.8$ & 0.68 & & & \\
\hline & $>0.79$ & 101 & 27 & $21.4-32.5$ & & & & \\
\hline \multirow[t]{2}{*}{ Sodium post-TACE $1^{\mathrm{a}} \mathrm{mEq} / \mathrm{L}$} & $\leq 140$ & 105 & 26 & $22.5-29.5$ & 0.28 & & & \\
\hline & $>140$ & 102 & 29 & $24.6-33.4$ & & & & \\
\hline \multirow[t]{2}{*}{ PT post-TACE $1^{\mathrm{a}} \%$} & $\leq 82$ & 106 & 27 & $22.9-31.1$ & 0.21 & & & \\
\hline & $>82$ & 102 & 28 & $22.8-33.1$ & & & & \\
\hline \multirow[t]{4}{*}{ Ascites post-TACE 1} & No & 189 & 28 & $25.5-30.5$ & $<0.001$ & 0.41 & $0.25-0.7$ & 0.001 \\
\hline & Yes & 27 & 17 & $8.6-25.4$ & & 0.38 & $0.24-0.63$ & $<0.001$ \\
\hline & & & & & & 0.43 & $0.27-0.68$ & $<0.001$ \\
\hline & & & & & & 0.37 & $0.23-0.58$ & $<0.001$ \\
\hline \multirow[t]{2}{*}{ Progressive disease to TACE-1 (mRECIST) } & No & 176 & 28 & $25.5-30.5$ & 0.03 & & & \\
\hline & Yes & 35 & 23 & $20.8-25.2$ & & & & \\
\hline \multirow[t]{5}{*}{ RECIST } & $C R$ & 55 & 28 & $20.8-35.1$ & $<0.001$ & & & \\
\hline & PR & 97 & 29 & $26.1-31.8$ & & & & \\
\hline & SD & 24 & 26 & $18.04-33.9$ & & & & \\
\hline & PD & 35 & 23 & $20.1-25.2$ & & & & \\
\hline & Not available & 5 & 2 & $0-4.2$ & & & & \\
\hline \multirow[t]{2}{*}{ Objective response } & No & 64 & 23 & $20.2-25.8$ & 0.01 & 0.67 & $0.46-0.98$ & 0.04 \\
\hline & Yes & 152 & 29 & $26.3-31.7$ & & 0.68 & $0.47-0.99$ & 0.048 \\
\hline
\end{tabular}

The model 4 uses only three variables, all of them post-TACE, with significant thresholds in two variables (albumin $35 \mathrm{~g} / \mathrm{L}$, AFP $100 \mathrm{ng} / \mathrm{mL}$ ) and appearance of ascites CI Confidence interval, HR Hazard ratio, TACE Transarterial chemoembolization, BCLC Barcelona Clinic Liver Cancer, CSPH Clinically significant portal hypertension., AFP Alphafetoprotein, Bil Bilirubin, Alb Albumin, AP Alkaline phosphatase, $H b$ Hemoglobin, CBCT Cone-beam computed tomography, EV Esophageal varices. ${ }^{\text {a }}$ The median values were used as a cut-off for continuous variables. ${ }^{b}$ Tumor size estimated by AUROC. $\triangle$ Bil, $\triangle$ AP, $\triangle$ AFP, and $\Delta$ alb are calculated by the subtraction of pre-TACE from post-TACE variables In the T1 period multivariate analysis includes basal (preTACE-1) variables statistically significant and those considered clinically relevant, together with significant variables of T1 period. Five models have been developed

Model 1: basal albumin $\leq 40 \mathrm{~g} / \mathrm{L}$ (median value), basal AP $\leq 108 \mathrm{IU} / \mathrm{L}$ (median value), ascites preTACE, albumin posTACE $<38 \mathrm{~g} / \mathrm{L}$ (median value) and ascites posTACE

Model 2: tumor size $<3 \overline{6} .5 \mathrm{~mm}$ (cut-off estimated by AURŌC), basal AFP $<12.8 \mathrm{ng} / \mathrm{mL}$ (median value), basal AP $<108$ IU $\bar{L}$ (median value) and objective response

Model 3: tumor size $\overline{<} 36.5 \mathrm{~mm}$ (estimated by AUROC), basal AFP $<12.8 \overline{\mathrm{ng}} / \mathrm{mL}$ (median value), basal AP $<108$ IU/L (median value), objective response and ascites posTACE

Model 4: albumine postTACE $<35 \mathrm{~g} / \mathrm{L}$ (arbitrary), AFP $<100 \mathrm{ng} / \mathrm{mL}$ postTACE (arbitrary) and ascites posTĀCE

Model 5: basal AP $\leq 108 \mathrm{IU} / \mathrm{L}$ (median), AFP $\leq 100 \mathrm{ng} / \overline{\mathrm{m} L}$ postTACE (arbitrary) and ascites posTACE 


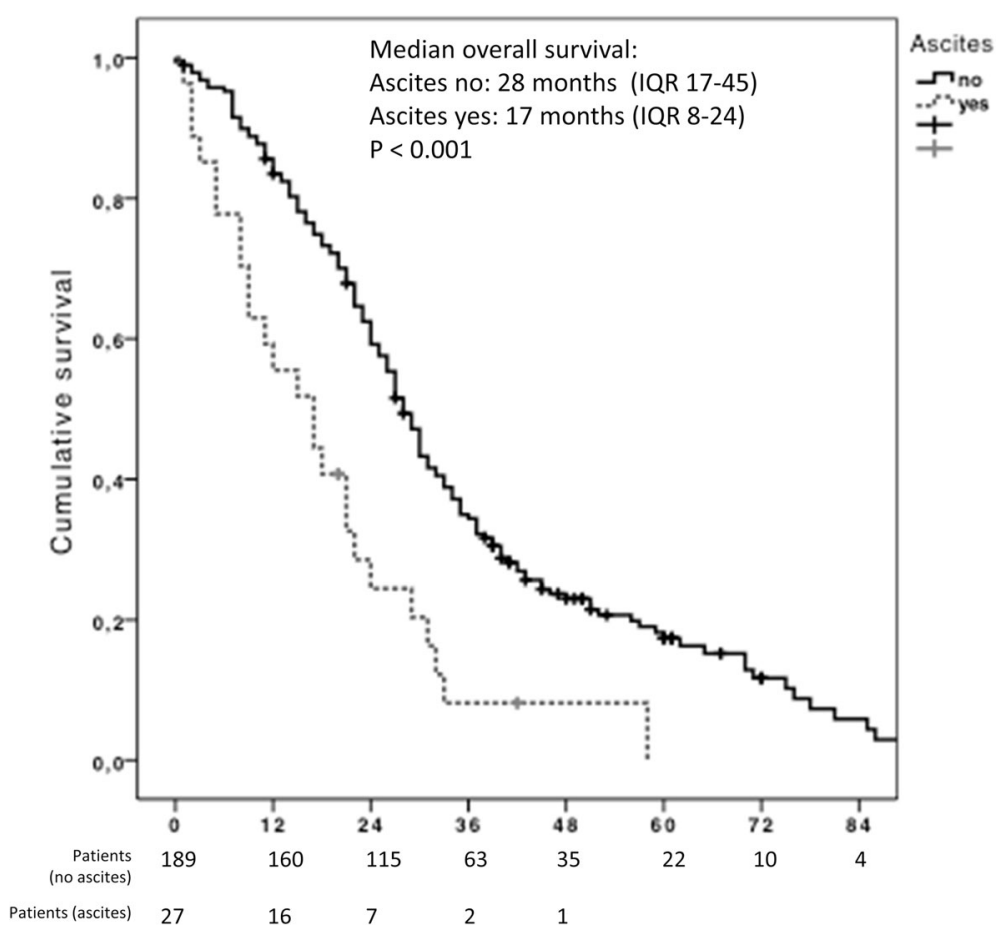

Fig. 3 Kaplan-Meier graph with the overall survival according to the development of ascites

In contrast, the main advantage of this study was the prospective collection of a large number of patients who were treated with a homogeneous protocol and the collection of adverse effects after DEB-TACE, including asymptomatic radiological abnormalities.

\section{Conclusions}

In conclusion, adverse events reduce OS following DEBTACE, especially when ascites is present. Although compensated chronic liver disease is a requirement for

Table 4 Predictors of development of early ascites based on multivariate Cox regression, censoring the time of follow-up at death, early ascites, or second DEB-TACE

\begin{tabular}{lllll}
\hline & $\begin{array}{l}p^{-} \\
\text {value }\end{array}$ & $\operatorname{Exp}(\mathrm{B})$ & \multicolumn{2}{c}{$\operatorname{Exp}(\mathrm{B}) 95 \% \mathrm{Cl}$} \\
\cline { 5 - 6 } & 0.35 & 0.34 & 0.05 & 2.99 \\
\hline CSPH (yes/no) & 0.43 & 0.61 & 0.1 & 2.10 \\
Esophageal varices (yes/no) & 0.20 & 1.80 & 0.730 & 4.46 \\
BCLC 0/ A (yes/no) & 0.15 & 1.53 & 0.85 & 2.74 \\
Bilirubin & 0.01 & 0.66 & 0.49 & 0.89 \\
Hemoglobin & 0.001 & 0.22 & 0.09 & 0.53 \\
Child A5 (yes / no) & 0.03 & 0.31 & 0.11 & 0.88 \\
Albumin & $<0.001$ & 0.12 & 0.04 & 0.32 \\
\hline Ascites prior to DEB-TACE & $<$
\end{tabular}

Model 1: Child A 5 plus Hemoglobin; Model 2: Hemoglobin plus prior ascites plus albumin

CSPH Clinically significant portal hypertension loco-regional therapy, the appearance of early ascites seems to be related to the history of prior ascites, lower haemoglobin levels and lower albumin. These factors could be relevant for properly selecting the best candidates for DEB-TACE when different therapeutic options are available.

\section{Supplementary information}

Supplementary information accompanies this paper at https://doi.org/10. 1186/s12876-020-01307-x.

Additional file 1 Supplementary Figure 1. probability of death in an average individual.

Additional file 2 Supplementary Table 1. Post-DEB-TACE events. Additional file $\mathbf{3}$ Supplementary Table $\mathbf{2}$. Variable values in the posTACE time (t1).

Additional file 4 Supplementary Table 3. Baseline characteristics associated with the development of early ascites.

Additional file $\mathbf{5}$ Supplementary Table 4. Time dependent-covariate analysis. Univariate model.

Additional file 6 Supplementary Table 5. Time-dependent multivariate analysis.

Additional file 7 Supplementary Table 6. Cohort studies on TACE/ DEB-TACE focused on alcohol etiology and survival.

\section{Abbreviations}

AFP: Alpha-fetoprotein; AP: Alkaline phosphatase; BCLC: Barcelona Clinic Liver Cancer; CBCT: Cone-beam computed tomography; Cl: Confidence interval; CT: Computed tomography; CR: Complete response; CSPH: Clinically significant portal hypertension; CDR: Disease control rate; DEB-TACE: Drugeluting embolic chemoembolization; EASL: European Association for the 
Study of the Liver; HCC: Hepatocellular carcinoma; HR: Hazard ratio; IQR: Interquartile range; mRECIST: Modified Response Evaluation Criteria in Solid Tumors; OR: Objective response; OS: Overall survival

\section{Acknowledgements}

Susana Díaz-Coto and Pablo Martínez-Camblor (statistical support).

\section{Authors' contributions}

Concept and design of the study: MV and MP; data collection: MP, SS, AM, CAN, MLGD, VC, JER, FV; statistical analysis: MP, MR, MV; analysing the results and writing of article: MP, SS, AM, JER, SMCG, MR, MV. All authors approved the last version of the manuscript.

\section{Funding}

None.

\section{Availability of data and materials}

The datasets used and/or analysed during the current study are available from the corresponding author on reasonable request.

\section{Ethics approval and consent to participate}

The protocol conformed to the ethical guidelines of the 1975 Declaration of Helsinki and was approved by the Ethics Committee of the Hospital Universitario Central de Asturias (Approval No. 120/19). No specific individual consent was obtained regarding the publication of data due to the retrospective nature of the publication.

\section{Consent for publication}

\section{Not applicable.}

\section{Competing interests}

Pipa-Muñiz M, Sanmartino S, Mesa A, Cadahía V, Rodríguez JE, Vega F, and Costilla-García SM: none. Álvarez Navascués C: speaking fees and advisory roles for Gilead, Abbvie, and Intercept. González-Dieguez ML: speaker fees from Gilead, Abbvie and Novartis and consultancy fees from Gilead. Manuel Rodríguez M: speaking fees and advisory fees from Gilead, Abbvie, Intercept, and MSD. Varela M: speaker fees from Bayer and Gilead; consultancy fees from Roche, Bristol-Myers-Squibb, SIRTEX, Bayer, IPSEN, and BTG-Boston.

\section{Author details}

'Division of Gastroenterology and Hepatology, Hospital de Cabueñes, Gijón, Spain. ${ }^{2}$ Radiology Department, Hospital Universitario Central de Asturias, Oviedo, Spain. ${ }^{3}$ Liver Unit, Hospital Universitario Central de Asturias, 33011 Oviedo, Spain. ${ }^{4}$ Universidad de Oviedo, Oviedo, Spain.

\section{Received: 10 December 2019 Accepted: 18 May 2020}

\section{Published online: 01 June 2020}

\section{References}

1. Bray F, Ferlay J, Soerjomataram I, Siegel RL, Torre LA, Jemal A. Global cancer statistics 2018: GLOBOCAN estimates of incidence and mortality worldwide for 36 cancers in 185 countries. CA Cancer J Clin. 2018;68(6):394-424.

2. Fact Sheets by Population-Globocan-IARC [Internet]. http://globocan.iarc.fr/ Pages/fact sheets population.aspx..

3. European Association for the Study of the Liver. EASL clinical practice guidelines: management of hepatocellular carcinoma. J Hepatol. 2018;69: 182-236.

4. Marrero JA, Kulik LM, Sirlin CB, et al. Diagnosis, staging, and Management of Hepatocellular Carcinoma: 2018 practice guidance by the American Association for the Study of Liver Diseases. Hepatology. 2018;68:723-50.

5. Forner A, Reig M, Bruix J. Hepatocellular carcinoma. Lancet. 2018 Mar 31; 391(10127):1301-14

6. Varela M, Real Ml, Burrel M, et al. Chemoembolization of hepatocellular carcinoma with drug eluting beads: efficacy and doxorubicin pharmacokinetics. J Hepatol. 2007:46:474-81.

7. Poon RT, Tso WK, Pang RW, et al. A phase I/II trial of chemoembolization for hepatocellular carcinoma using a novel intra-arterial drug-eluting bead. Clin Gastroenterol Hepatol. 2007;5(9):1100-8.

8. Lammer J, Malagari K, Vogl T, et al. Prospective randomized study of doxorubicin-eluting-bead embolization in the treatment of hepatocellular carcinoma: results of the PRECISION V study. Cardiovasc Intervent Radiol. 2010;33:41-52.

9. Golfieri R, Giampalma E, Renzulli M, et al. Randomised controlled trial of doxorubicin-eluting beads vs. conventional chemoembolisation for hepatocellular carcinoma. Br J Cancer. 2014;111:255-64.

10. Kim NH, Lee T, Cho YK, Kim BI, Kim HJ. Impact of clinically evident portal hypertension on clinical outcome of patients with hepatocellular carcinoma treated by transarterial chemoembolization. J Gastroenterol Hepatol. 2018; 33(7):1397-406.

11. Sieghart W, Hucke F, Pinter $M$, et al. The ART of decision making: retreatment with Transarterial chemoembolization in patients with hepatocellular carcinoma. Hepatology. 2013;57(6):2261-73.

12. Kadalayil $L$, Benini $R$, Pallan $L$, et al. A simple prognostic scoring system for patients receiving transarterial embolisation for hepatocellular cancer. Ann Oncol. 2013;24(10):2565-70.

13. Adhoute $X$, Penaranda G, Naude S, et al. Retreatment with DEB-TACE: the ABCR SCORE, an aid to the decision-making process. J Hepatol. 2015;62(4):855-62.

14. Cabibbo G, Enea M, Attnasio M, Bruix J, Craxì A, Cammà C. A meta-analysis of survival rates of untreated patients in randomized clinical trials of hepatocellular carcinoma. Hepatology. 2010;51(4):1274-83.

15. García-Tsao G, Abraldes JG, Berzigotti A, Bosch J. Portal hypertensive bleeding in cirrhosis: risk stratification, diagnosis, and management: 2016 practice guidance by the American Association for the Study of Liver Diseases. Hepatology. 2017;65(1):310-35.

16. Prajapati HJ, Xing M, Spivey JR, et al. Survival, efficacy, and safety of small versus large doxorubicin drug-eluting beads DEB-TACE chemoembolization in patients with unresectable HCC. AJR Am J Roentgenol. 2014;203(6): W706-14

17. Lencioni R, Llovet JM. Modified RECIST (mRECIST) assessment for hepatocellular carcinoma. Semin Liver Dis. 2010;30(1):52-60.

18. Forner A, Gilabert M, Bruix J, Raoul JL. Treatment of intermediate-stage hepatocellular carcinoma. Nat Rev Clin Oncol. 2014;11(9):525-35.

19. Berzigotti A, Reig M, Abraldes JG, Bosch J, Bruix J. Portal hypertension and the outcome of surgery for hepatocellular carcinoma in compensated cirrhosis: a systematic review and meta-analysis. Hepatology. 2015;61(2):526-36.

20. Choi JW, Chung JW, Lee DH, et al. Portal hypertension is associated with poor outcome of transarterial chemoembolization in patients with hepatocellular carcinoma. Eur Radiol. 2018;28(5):2184-93.

21. Malagari K, Pomoni M, Moschouris $\mathrm{H}$, et al. Chemoembolization with doxorubicin-eluting beads for unresectable hepatocellular carcinoma: fiveyear survival analysis. Cardiovasc Intervent Radiol. 2012;35(5):1119-28.

22. Burrel M, Reig M, Forner $A$, et al. Survival of patients with hepatocellular carcinoma treated by transarterial chemoembolisation (DEB-TACE) using drug eluting beads. Implications for clinical practice and trial design. J Hepatol. 2012:56(6):1330-5.

23. Terzi E, Terenzi L, Venerandi L, Croci L. The ART score is not effective to select patients for transarterial chemoembolization retreatment in an Italian series. Dig Dis. 2014;32(6):711-6.

24. Chen L, Ni CF, Chen SX, et al. A modified model for assessment for retreatment with Transarterial chemoembolization in Chinese hepatocellular carcinoma patients. J Vasc Interv Radiol. 2016;27(9):1288-97.

25. Facciorusso A, Mariani L, Sposito C, et al. Drug-eluting beads versus conventional chemoembolization for the treatment of unresectable hepatocellular carcinoma. J Gastroenterol Hepatol. 2016;31(3):645-53.

26. Pipa-Muñiz M, Castells L, Pascual $S$, et al. The ART-SCORE is not an effective tool for optimizing patient selection for DEB-TACE retreatment. A multicentre Spanish study. Gastroenterol Hepatol. 2017;40(8):515-24.

27. Zhang $Y Q$, Jiang $L$, Wen J, et al. Comparison of a-fetoprotein criteria and modified response evaluation criteria in solid tumors for the prediction of overall survival of patients with hepatocellular carcinoma after Transarterial chemoembolization. J Vasc Interv Radiol. 2018;29(12):1654-61.

28. Biolato M, Gallusi G, lavarone M, et al. Prognostic ability of BCLC-B subclassification in patients with hepatocellular carcinoma undergoing Transarterial chemoembolization. Ann Hepatol. 2018;17(1):110-8.

29. Sánchez-Delgado J, Vergara M, Machlab S, et al. Analysis of survival and prognostic factors in treatment of hepatocellular carcinoma in Spanish patients with drug-eluting bead transarterial chemoembolization. Eur J Gastroenterol Hepatol. 2018;30(12):1453-60.

30. Moreau $R$, Jalan $R$, Ginés $P$, et al. Acute-on-chronic liver failure is a distinct syndrome that develops in patients with acute decompensation of cirrhosis. Gastroenterology. 2013;144:1426-37. 
31. Shah ND, Ventura-Cots M, Abraldes JG, et al. Alcohol related Liver Disease is Rarely Detected at Early Stages Compared With Liver Diseases of Other Etiologies Worldwide. Clin Gastroenterol Hepatol. 2019;S1542-3565(19): 30073-4.

32. Marot A, Henrion J, Knebel JF, Moreno C, Deltenre P. Alcoholic liver disease confers a worse prognosis than HCV infection and non-alcoholic fattyliver disease among patients with cirrhosis: an observational study. PLoS One. 2017;12(10):e0186715.

33. Adhoute X, Pénaranda G, Raoul JL, et al. Barcelona clinic liver cancer nomogram and others staging/scoring systems in a French hepatocellular carcinoma cohort. World J Gastroenterol. 2017;23(14):2545-55.

34. Collette $S$, Bonnetain F, Paoletti $X$, et al. Prognosis of advanced hepatocellular carcinoma: comparison of three staging systems in two French clinical trials. Ann Oncol. 2008;19(6):1117-26.

35. Ricke J, Klümpen $\mathrm{HJ}$, Amthauer $\mathrm{H}$, et al. Impact of combined selective internal radiation therapy and sorafenib on survival in advanced hepatocellular carcinoma. J Hepatol. 2019;71:1164-74.

36. Chen ZH, Zhang XP, Cai XR, et al. The predictive value of albumin-toalkaline phosphatase ratio for overall survival of hepatocellular carcinoma patients treated with trans-catheter arterial chemoembolization therapy. J Cancer. 2018;9(19):3467-78.

37. Wu X, Chen R, Zheng W, et al. Comprehensive analysis of factors affecting clinical response and short-term survival to drug-eluting bead Transarterial chemoembolization for treatment in patients with liver Cancer. Technol Cancer Res Treat. 2018;17:1533033818759878.

\section{Publisher's Note}

Springer Nature remains neutral with regard to jurisdictional claims in published maps and institutional affiliations.

Ready to submit your research? Choose BMC and benefit from:

- fast, convenient online submission

- thorough peer review by experienced researchers in your field

- rapid publication on acceptance

- support for research data, including large and complex data types

- gold Open Access which fosters wider collaboration and increased citations

- maximum visibility for your research: over $100 \mathrm{M}$ website views per year

At $\mathrm{BMC}$, research is always in progress.

Learn more biomedcentral.com/submissions 